\title{
Bovine tuberculosis and its risk factors among dairy cattle herds in and around Bahir Dar City, Northwest Ethiopia
}

\author{
Anwar Nuru,,$^{1,4^{*}}$ Gezahegne Mamo, ${ }^{3}$ Leakemariam Teshome, ${ }^{2}$ Aboma Zewdie, ${ }^{1}$ Girmay \\ Medhin, ${ }^{1}$ Rembert Pieper ${ }^{5}$ and Gobena Ameni ${ }^{1}$ \\ ${ }^{1}$ Aklilu Lemma Institute of Pathobiology, Addis Ababa University, P.O. Box 1176, Addis Ababa, \\ Ethiopia \\ ${ }^{2}$ Animal Diseases Investigation and Diagnostic Laboratory, Amhara Region Bureau of Agricul- \\ ture, P. O. Box 70, Bahir Dar, Ethiopia \\ ${ }^{3}$ College of Veterinary Medicine and Agriculture, Addis Ababa University, P.O. Box 34, Debre Zeit, \\ Ethiopia \\ ${ }^{4}$ Faculty of Veterinary Medicine, University of Gondar, P.O. Box 346, Gondar, Ethiopia \\ ${ }^{5}$ J. Craig Venter Institute, 9704 Medical Center Drive, Rockville, Maryland, United States \\ ${ }^{*}$ Corresponding author: Faculty of Veterinary Medicine, University of Gondar, P.O. Box 346, \\ Gondar,Ethiopia,Email: hamduanwar@yahoo.com or anwar.nuru@uog.edu.et
}

\section{Abstract}

A cross-sectional study focusing on the prevalence and assessment of the associated risk factors of bovine tuberculosis (BTB) among dairy cattle herds was conducted from 2012 to 2014 in Bahir Dar City and the surrounding districts. Comparative intradermal tuberculin test (CIDT) and interviewer administer questionnaire were used for conducting this study. Animal prevalence of BTB was $3.55 \%$ (95\% confidence interval (CI): $2.26-4.84)$ at $>=2 \mathrm{~mm}$ cut-off value and $1.27 \%(95 \% \mathrm{CI}: 0.49-2.05)$ at $>=4 \mathrm{~mm}$ cut-off value. Similarly, herd prevalence was $12.5 \%$ (95\% CI: $7.78-17.2)$ at $>=2 \mathrm{~mm}$ cut-off value and $5.21 \%$ (95\%CI: $2.04-8.38$ ) at $>=4 \mathrm{~mm}$ cut-off value. In a multivariable logistic regression analysis, being cross breed (adjusted OR=3.33, 95\%CI: $0.33-34.0$ ) and having poor body condition (adjusted $\mathrm{OR}=467,95 \% \mathrm{CI}: 35.9-6086$ ) were identified as animal level risk factors for higher tuberculin reactivity. At herd level increased risk for CIDT positivity was recorded at intensive dairy herds (adjusted OR=10.8: 95\% CI: 1.32-88.1) as compared to smallholder dairy herds. In summary, the present study revealed overall low prevalence of BTB in dairy cattle in the study area. However, comparatively higher proportion of skin reactors recorded at upgraded breeds and intensive dairy herds. This warrants the need for the designing of practically acceptable control strategy.

Keywords: Bovine tuberculosis, Dairy cattle herd, Prevalence, Risk factor

http://dx.doi.org/10.4314/evj.v19i2.3 


\section{Introduction}

BTB is an infectious disease caused principally by Mycobacterium (M.) bovis, which is member of the Mycobacterium tuberculosis complex (MTC). Although cattle are susceptible to $M$. bovis infection and are the preferred host for $M$. bovis, the disease has been reported in many other domesticated animals, wildlife and humans (De Lisle et al., 2002; Wuhib Ayele et al., 2004; Renwick et al., 2007). Aerosol exposure to $M$. bovis is believed to be the most frequent mode of transmission in cattle, but infection by ingestion has also been reported previously (Biet et al., 2005). Human beings can also acquire the infection either by inhalation or ingestion (Cosivi et al., 1998; Wilkins et al., 2008). Thus, BTB is a disease of major socio-economic importance, with an impact of loss in animal productivity, international trade of animals and animal products (Zinsstag et al., 2006).

Ethiopia is ranked top in the list of African countries with large livestock populations and it has been contributing considerable portion to the economy of the country. The 2012/13 livestock survey estimated the total number of cattle, sheep and goat population in the country to be 54 million, 25.5 million and 24 million, respectively. And Amhara Regional State owns 13.8 million cattle, 8.8 million sheep and 5.1 million goats (CSA, 2013). About $98.9 \%$ of the total cattle populations in the country were local breeds and the remaining were hybrid $(0.94 \%)$ and exotic $(0.11 \%)$ breeds. Among a total of 3.4 million cattle population aged $\leq 3-10$ years, $12.5 \%$ were used for milk production (CSA, 2013). Even though the livelihood of the people in Ethiopia is extremely dependent on livestock, several constraints including feed shortage, poor genetic performance and diseases prevalence are limiting the livestock production and productivity. BTB is one among the major disease problems reported widely in cattle from different regions of the country (Balako Gumi et al., 2011; Balako Gumi et al., 2012; Petros Admasu et al., 2014; Worku Tigre et al., 2011; Gebremedhin Romha et al., 2014; Tschopp et al., 2011; Rebuma Firdessa et al., 2012; Gezahegne Mamo et al., 2013; Fikre Zeru et al., 2014). However, most of these evidences are obtained from north, central and southern Ethiopia. To the best of our knowledge information on BTB among dairy herds in northwest Ethiopia is limited. The current study was designed to investigate the epidemiology of BTB and to assess animal level and herd level risk factors of BTB. 


\section{Materials and Methods}

\section{Study area}

The current study was conducted in Bahir Dar City and the surrounding towns, namely, Zenzelima, Meshenti, Tis Abay and Zege. Bahir Dar is a Capital City of Amhara Regional State and located in northwestern Ethiopia, approximately $578 \mathrm{~km}$ of Addis Ababa, having latitude $11^{\circ} 36^{\prime} \mathrm{N}$, longitude of $37^{\circ} 23^{\prime} \mathrm{E}$ and an elevation of 1800 meters above sea level. Based on the 2007 Census result (CSA, 2007), Bahir Dar Special Zone has a total population of 221,991 , of whom 180,174 (81.16\%) are urban inhabitants. Among the urban residents 155,428 are living in Bahir Dar City and the remaining resides in one of the other towns (i.e. Meshenti, Tis Abay and Zege towns). Livestock production is one of the agricultural activities that have been practiced by the local populations in the study area. The numbers of livestock by animal species in West Gojjam Zone including Bahir Dar Special Zone were estimated to be 2,182,636 cattle, 893,368 sheep and 339,858 goats (CSA, 2013), The study area has the second largest livestock population in Amhara Region next to North Gondar Zone. Intensive farming and smallholder dairy management systems are the types of dairy activities observed in the study area. The main feed sources for intensive dairy herds are agro-industrial by products (such as oil seed cakes, Bran, etc) and also purchased roughage. The primary objective of this dairy system is to sale milk as a means of additional cash income. Smallholder dairy herding in the study area is practiced mixed with crop farming and all feed requirements are derived from grazing pasture and roughage. Milk production is mainly from indigenous zebu cattle, which are kept by smallholder farming households.

\section{Study population}

The study animals were dairy cattle originated from intensive (urban and periurban dairy farms) and smallholder dairy herds. The intensive dairy farms comprised small and medium size dairy herds, ranges 4-34 cattle. Most of the intensive dairy farms were concentrated in and around Bahir Dar City and were raising cross-breed dairy cattle. The smallholder dairy herds were located mainly in Zenzelima, Meshenti, Tis Abay and Zege towns and the surrounding rural areas. The herd size ranged between $2-25$ cattle and they were managed under extensive system. The majority of milking cows were indigenous animals but small numbers of cross-breeds were also found. 
Young animals less than 6 months age, cows in late gestation period and clinically sick animals with any disease problem were not included in the study. The age of cattle was estimated by dentition (Torrell, 1998), information obtained from animal owners or farm records. The body condition of each animal was scored based on Nicholson and Butterworth (1986) and classified as poor (score, 1 to 2 ), medium (3 to 4 ) and good (greater than 5).

\section{Study design and study period}

The study design was cross-sectional and the study was conducted from 2012 to 2014 in Bahir Dar City and the surrounding districts of the Bahir Dar Special Zone.

\section{Sample size estimation and sampling of study animals}

Sample size was estimated using the formula (Thrusfield 1995), which is used to estimate prevalence in a given population. Thus, accordingly, a total of 192 herds were calculated to be enough to estimate the prevalence by considering the expected herd BTB prevalence of 15\% (Gobena Ameni and Erkihun Aklilu, 2007 ) with the precession $5 \%$ and $\mathbf{9 5 \%}$ confidence in the estimate. To recruit these herds volunteer dairy farm owners and households with smallholder dairy herds from the Bahir Dar City and the surrounding districts were registered and used as a sampling frame. Simple random sampling technique was applied to select dairy herds from the available sample frame. A total of 1279 cattle were available in the randomly selected 192 dairy herds. Among these cattle only 788 fulfilled inclusion criterion and hence examined for BTB by the use of CIDT.

\section{Data collection}

Animal related potential risk factors (i.e. sex, age, breed, and body condition score) were recorded when the CIDT test was performed.. Dairy herd owners were also asked for TB related personal information (such as educational level, knowledge on BTB and its zoonotic implication, and family TB history) and herd characteristics (such as dairy herd management system, herd size, keeping of different animals together, introduction of new cattle in to the herd) using semi-structured questionnaire after they were well informed and oral consent was obtained from each owner. 


\section{Comparative Intradermal Tuberculin Test, CIDT}

CIDT was used to test animals for BTB. The test was performed by the intradermal injection of bovine purified protein derivative (B-PPD) and avian PPD (A-PPD) (supplied by Prionics Lelystad B. V., The Netherlands) after the skin was shaved and the thickness measured with a caliper. The PPDs were injected into two sites in middle third of the neck (about $12 \mathrm{~cm}$ apart).. One site was injected with an aliquot of $0.1 \mathrm{ml}$ of $2500 \mathrm{IU} / \mathrm{ml} \mathrm{B-PPD}$ and the other was with $0.1 \mathrm{ml}$ of $2500 \mathrm{IU} / \mathrm{ml}$ A-PPD. For determining the reactions on the skin (indurations) at the injection sites the skin-fold thickness of each injection site was re-measured $72 \mathrm{~h}$ after intradermal injection. All skin measurements and test readings were carried out by the same person. Interpretation of the test result was made at two different cut-off points i.e. the animal was considered to be positive if the skin reaction at the $\mathrm{PPD}-\mathrm{B}$ site minus the skin reaction at the PPD-A is $\geq 2 \mathrm{~mm}$ (Gobena Ameni et al., 2008) or $\geq 4 \mathrm{~mm}$ (OIE, 2008). However, if a reaction to B-PPD tuberculin was equal to or less than the reaction to A-PPD the result was interpreted as negative reaction. A dairy herd was considered positive if at least one tuberculin reactor animal was present in that herd. Each animal injected with tuberculin was de-wormed with Albendazole (7.5 $\mathrm{mg} / \mathrm{kg}$ ) as part of the support by the project.

\section{Data analysis}

Data collected during the study period were analyzed using STATA version 12 (Stata Corp., Collage station, TX). Fisher's exact test was used to assess if there is statistically significant association between target background characteristic and skin test reaction. The degrees of these associations were quantified using crude and adjusted odds ratio obtained from logistic regression models. Statistical significance was assumed if the confidence interval (CI) did not include one among its values or whenever $p$-value was less than $5 \%$.

\section{Results}

\section{General information on the study animals}

A total of 788 cattle from 192 dairy herds in Bahir Dar City and the surrounding districts of Bahir Dar Special Zone were examined for BTB with CIDT test. Mean age of the study animals was 5.1 years (95\%CI: 4.85-5.34). The sex of majority of the study animals was female $(87.9 \% ; 693 / 788)$. The breed composition was cross-breed (48\%) and zebu (52\%). Of the total, $42.3 \%(333 / 788)$ 
were from 92 urban and peri-urban dairy farms, which mainly concentrated in Bahir Dar City. The remaining 57.7\% (455/788) cattle were originated from 100 smallholder dairy herds localized in and around Zenzelima, Chis Abay, Meshenti and Zege towns.

\section{Animal prevalence and associated host risk factors}

On the basis of CIDT test the overall individual prevalence of BTB at $\geq 2 \mathrm{~mm}$ and $\geq 4 \mathrm{~mm}$ cut-off points were $3.55 \%$ (95\%CI: $2.26-4.84)$ and $1.27 \%$ (95\%CI: 0.49-2.05), respectively. At $\geq 4 \mathrm{~mm}$ cut-off, the prevalence of BTB was affected by breed $(p=0.009)$ and body condition $(p<0.001)$ of the study animals (Table 1$)$.

Table 1: Association of selected host risk factors to skin test positivity of individual animals at $\geq 4 \mathrm{~mm}$ cutoff point.

\begin{tabular}{llll}
\hline Host factor & $\begin{array}{l}\text { Number } \\
\text { animals tested }\end{array}$ & $\begin{array}{l}\text { Number of positive } \\
\text { animals n(\%) }\end{array}$ & p-value \\
\hline Breed & & $1(0.24)$ & 0.009 \\
Local & 410 & $9(2.38)$ & \\
Cross & 378 & & \\
Sex & & 0 & 0.619 \\
Male & 95 & $10(1.44)$ & \\
Female & 693 & & \\
Age (years) & & $1(0.58)$ & \\
$<2$ & 172 & $2(0.92$ & \\
$2-5$ & 217 & $6(2.31)$ & \\
$5-9$ & 260 & $1(0.72)$ & $<0.001$ \\
$>9$ & 139 & & \\
BCS & & $1(0.28)$ & \\
Good & 362 & $2(0.48)$ & \\
Medium & 414 & $7(58.3)$ & \\
Poor & 12 & & \\
\hline
\end{tabular}

$\mathrm{n}=$ number of positive; $\mathrm{BCS}=$ Body condition scoring; $\mathrm{p}$-values presented at $\mathbf{9 5 \%}$ confidence interval and $\mathrm{p} \leq 0.05$ considered statistically significant.

Results from bivariate and multivariable logistic regression analysis are summarized in Table 2. After adjusting for bread, age and body condition, animal with poor body condition as compared to animal with good body condition was identified as a significant risk for being positive reactor although the precision of the estimate was low as indicated by wide confidence interval (Adjusted $\mathrm{OR}=467 ; 95 \% \mathrm{CI}=35.9-6086$ ). 
Table 2: Logistic regression analysis of individual animal tuberculin reactors with selected host related risk factors at $4 \mathrm{~mm}$ cutoff point.

\begin{tabular}{lllll}
\hline Host factor & $\begin{array}{l}\text { Number of } \\
\text { animals tested }\end{array}$ & $\begin{array}{l}\text { Number of } \\
\text { positive animals } \\
\mathbf{n}(\%)\end{array}$ & $\begin{array}{l}\text { COR } \\
\mathbf{( 9 5 \%} \text { CI) }\end{array}$ & $\begin{array}{l}\text { AOR } \\
(\mathbf{9 5 \%} \text { CI) }\end{array}$ \\
\hline $\begin{array}{l}\text { Breed } \\
\text { Local }\end{array}$ & 410 & $\mathbf{1}(0.24)$ & 1.0 & 1.0 \\
Cross & 378 & $9(2.38)$ & $9.98(1.26-79.1)$ & $3.33(0.33-34.0)$ \\
Age (years) & & & & \\
$<2$ & 172 & $1(0.58)$ & 1.0 & 1.0 \\
$2-5$ & 217 & $2(0.92$ & $1.59(0.14-17.7)$ & $0.29(0.02-5.45)$ \\
$5-9$ & 260 & $6(2.31)$ & $4.04(0.48-33.9)$ & $0.72(0.06-9.12)$ \\
$>9$ & 139 & $1(0.72)$ & $1.24(0.08-20.0)$ & $0.53(0.02-14.2)$ \\
BCS & & & & \\
Good & 362 & $1(0.28)$ & 1.0 & 1.0 \\
Medium & 414 & $2(0.48)$ & $1.75(0.16-19.4)$ & $1.94(0.17-22.2)$ \\
Poor & 12 & $7(58.3)$ & $505(52.0-4909)$ & $357(33.9-3753)$ \\
\hline
\end{tabular}

$\mathrm{n}=$ number of positive; $\mathrm{BCS}=$ Body condition scoring; $\mathrm{COR}=\mathrm{Crude}$ Odds Ratio; $\mathrm{AOR}=$ Adjusted Odds Ratio; CI:

Confidence interval.

\section{Herd level prevalence and associated risk factors}

Herd prevalence was $12.5 \%$ (95\%CI: $7.78-17.2)$ at $\geq 2 \mathrm{~mm}$ cut-off and $5.21 \%$ (95\% CI: 2.04-8.38) at $\geq 4 \mathrm{~mm}$ cut-off value. After adjusting for herd size, practice of keeping other animals with cattle and introduction of new animal, the odds of herd positivity in a confined management system was 10.8 times higher than that of smallholder management system (95\%CI: 1.32-88.1) (Table 3).

Table 3: Bivariate and multivariate logistic regression analysis for potential herd risk factors at $>4 \mathrm{~mm}$ cutoff point.

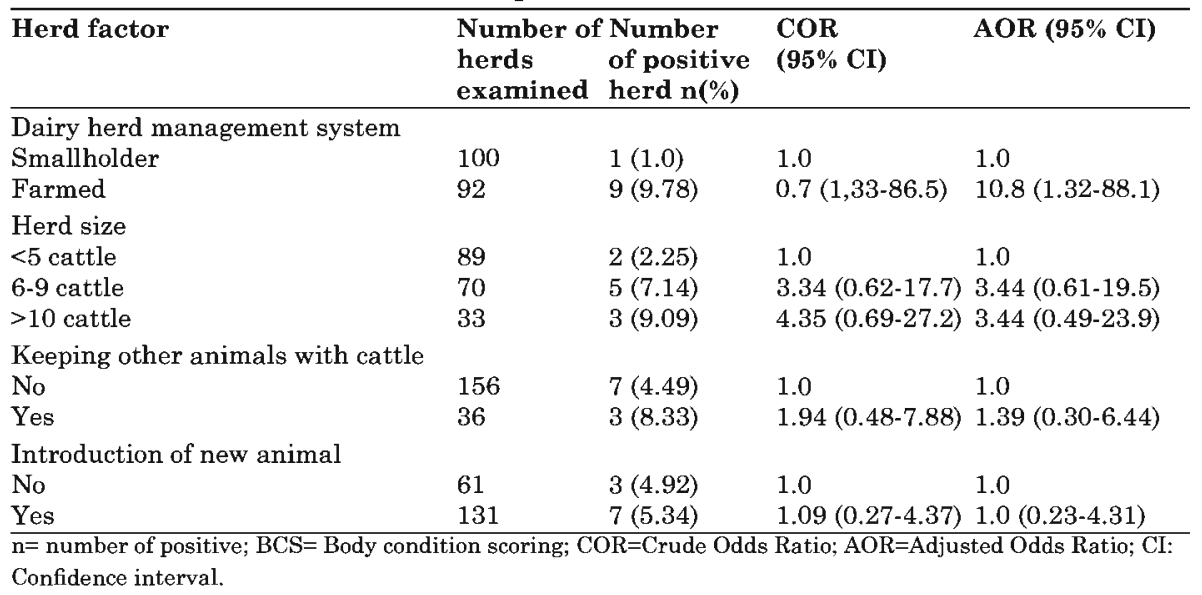


A total of 192 herd owners/households were also interviewed to assess their awareness on BTB and its transmission to humans. The mean age of the respondents was 39.1 (95\%CI: $36.7-41.4$ ) and the proportions of male to female were $(86.5 \%$ and $13.5 \%)$. Results of the descriptive statistics analysis indicated that among the interviewed, $75 \%(144 / 192)$ of the respondents did not have knowledge on BTB and its zonootic implication. About 19.3\% (37/192) had experienced at least one human TB case in the family in the previous last five years.

\section{Discussion}

\section{Animal prevalence and associated host risk factors}

The current animal level BTB prevalence of $3.55 \%$ at $\geq 2 \mathrm{~mm}$ cut-off is comparable to the previously reported prevalence of $3.0 \%$ and $4.02 \%$ by other studies in different sites of Ethiopia (Tschopp et al., 2009; Firaol Tamiru et al., 2013) but significantly lower than the previously reported prevalence of $7.0 \%$ in southern Ethiopia (Balako Gumi et al., 2011), 18\% in Afar (Gezahegne Mamo et al., 2013) and 6.8\% Meskan, Gurage region, central Ethiopia (Tschopp et al., 2011). Animal prevalence of $1.27 \%$ recorded at $\geq 4 \mathrm{~mm}$ cut-off value was similar to the prevalence of $2.0 \%, 1.0 \%$ and $1.56 \%$ in Ethiopia (Balako Gumi et al., 2012; Firaol Tamiru et al., 2013; Petros Admasu et al., 2014) and $2.6 \%$ in Zambia (Pandey et al., 2013) while it was lower than $11.0 \%, 23.7 \%$, $5.5 \%, 30.0 \%, 11.0 \%, 4.3 \%$ and $11.3 \%$ in Ethiopia (Gobena Ameni and Erkihun Aklilu, 2007; Elias Kebede et al., 2008; Gumi et al., 2011; Rebuma Firdessa et al., 2012; Gezahegne Mamo et al., 2013; Gebremedhin Romha et al., 2014; Fikre Zeru et al., 2014), 7.13\% in Ecuador (Proaño-Perez et al., 2009), 14.3\% in India (Thakur et al., 2010) and 5.9\% in Bangladesh (Mondal et al., 2014). The variation observed among the studies might be attributed to differences in management practices, production system, types of cattle breeds largely involved in the study, or differences in ecological zones. Moreover, the herd size in the majority of our study herds was small and maximum two tuberculin positive cases was recorded in few herds. This might also explain the low prevalence recorded in the present study compared to other studies, which reported high BTB prevalence.

Similar to other recent studies in Ethiopia (Petros Admasu et al., 2014; Gebremedhin Romha et al., 2014; Fikre Zeru et al., 2014) and India (Thakur et al., 2010), there was strong association between breed type and tuberculin skin test positivity in the present study at $\geq 4 \mathrm{~mm}$ cut-off value. The probable 
justification could be associated to the relative resistance of the zebu cattle to TB as compared to Holstein and other cross breeds (O'Reilly and Daborn, 1995; Gobena Ameni et al., 2007; Cadmus et al., 2010). However our finding differed from the reports of Elias Kebede et al. (2008) and Rebuma Firdessa et al. (2012) in such a way that their study herds were composed of largely Holstein and cross breed dairy cows exclusively kept under intensive management system.

Although the estimate is less precise, study body condition score in the current study was significantly associated with positive skin reactivity. Animals with poor body condition status were associated to the increased risk of bovine tuberculin positivity as compared to good body conditioned cattle. This result is in agreement with the previous studies (Elias Kebede et al., 2008; Petros Admasu et al., 2014; Fikre Zeru et al., 2014) although other findings did not report similar result (Rebuma Firdessa et al. (2012). Poor body conditioned animals have relatively weak immunological responses to TB and subsequently susceptible to the infection (Griffin et al., 1993; O'Reilly and Daborn, 1995).

Analysis of sex and age in relation to bovine tuberculin positivity in the present study were found statistically not significant $(\mathrm{p}=0.619$ and $\mathrm{p}=0.444$, respectively). In agreement with some previous studies in Ethiopia (Elias Kebede et al., 2008; Petros Admasu et al., 2014) there was not significant association of age and sex with reactivity in the current study. Other previous Ethiopian studies (Gobena Ameni and Erkihun Aklilu, 2007; Elias Kebede et al., 2008; Balako Gumi et al., 2011; Gezahegne Mamo et al., 2013), a study from Ecuador (Proano-Perez et al. (2009) and another study from India (Thakur et al. 2010) reported significant association between age and positive reaction. Likewise an Ethiopian study (Fikre Zeru et al. 2014) reported significant association between sex and tuberculin skin test positivity. In our study, the majority of cattle were female $(87.9 \%, 693 / 788)$ and age group between $5-9$ years $(33 \%, 260 / 788)$, which may explain the observed variation.

\section{Herd level prevalence and associated risk factors}

The herd prevalence of $5.21 \%$ recorded in the present study was comparable with a recent report of $7.02 \%$ (Firaol Tamiru et al. 2013) but much lower than $41.9 \%, 51.4 \%, 50 \%, 44 \%, 15.3 \%$ and $20 \%$ reported by other recent Ethiopian studies (Balako Gumi et al., 2011; Worku Tigre et al., 2011; Rebuma Firdessa et al., 2012; Gezahegne Mamo et al., 2013; Gebremedhin Romha et al., 2014; Fikre Zeru et al., 2014). The disparity of herd prevalence reported among 
the different studies might be attributed to the differences in the available different epidemiological conducive conditions favored for the transmission of BTB (such as herd size, the level of intensive husbandry system practiced, the amount of susceptible breeds available in the herd, mobility and close contact between different susceptible animal species in the study area).

Significant association of dairy cattle management system and herd positivity observed in the current study is in agreement with the findings of earlier studies (Elias Kebede et al., 2008; Gebremedhin Romha et al., 2014; Fikre Zeru et al., 2014). A higher herd prevalence of BTB in intensive dairy herds as compared to smallholder in this study might be related to their confinement and breed type. In the current study nearly $100 \%$ of the animals were cross breeds. Previous authors also argued in the same ways (Gobena Ameni et al., 2006) and demonstrated that cattle kept under intensive conditions showed significantly higher prevalence as compared to those managed under extensive system. In contrast to our finding other studies (Elias Kebede et al., 2008; Gebremedhin Romha et al., 2014; Fikre Zeru et al., 2014) reported significant association between herd size and herd positivity. Likewise, significant associations were reported between herd positivity and keeping of other animals with cattle (Tschopp et al., 2009) and herd positivity with introduction of new cattle in to the herd (Tschopp et al., 2009; Proano-Perez et al., 2009).

In the present study the proportion of the respondents who had knowledge on BTB and its zoonotic implication were below $50 \%(25 \%, 48 / 192)$. This result is in line with the reports of (Gobena Ameni and Erkihun Aklilu, 2007; Worku Tigre et al., 2011; Firaol Tamiru et al., 2013; Gebremedhin Romha et al., 2014; Fikre Zeru et al., 2014), who indicated 35\%, 37.1\%, 80.7\%, 29.7\% and $30.8 \%$ level of awareness in their study subjects, respectively. The zoonotic risk of BTB is often associated with consumption of untreated milk and meat products as well as via aerosol in the proximity to livestock (Cosivi et al., 1998; Wilkins et al., 2008). This urges the integrated work of medical and veterinary personnel to build awareness with regard to BTB and its public health aspects in the study area.

\section{Conclusion}

Animal and herd prevalence of BTB recorded in the present study were much lower than the reports of many earlier studies in Ethiopia. Among potential host factors breed and body condition were significantly associated with 
individual animal skin test reactivity. Similarly, being cross breed and poor body condition were identified as animal level risk factors for being positive reactors. Being farmed under intensive management system had over tenfold risk for herd positivity compared to smallholder dairy herds managed under extensive system. The observed higher proportion of skin reactors at upgraded dairy cattle and intensive dairy farms as compared to zebu cattle and smallholder dairy herds warrants for designing practically acceptable control strategy.

\section{Acknowledgements}

This study was jointly funded by the National Institute of Health (NIH, USA) through its H3Africa Program and grant number: U01HG00747201, Addis Ababa University through its Thematic Research Program, and Tiru Alem, University of Gondar. The authors acknowledge the incredible support of Nega Nugusie, Samuel Bekele and Yitbarek Getachew for assisting the tuberculin skin test. We thank also members of Bahir Dar Special Zone Agricultural Office, who contributed in organizing our activities at their respective sites.

\section{References}

Admasu, P., Berihun, W. and Niguse, A., 2014. Prevalence of bovine tuberculosis in dairy cattle of Yeki District, Southern Ethiopia. African J. Basic \& Appl. Sci, 6 (5), 135-140.

Ameni, G., Aseffa, A., Engers, H., Young, D., Hewinson, G and Vordermeier, M., 2006. Cattle husbandry in Ethiopia is a predominant factor affecting the pathology of bovine tuberculosis and gamma interferon responses to mycobacterial antigens. Clin Vaccine Immunol, 13, 1030-1036.

Ameni, G., Hewinson, G., Aseffa, A., Young, D. and Vordermeier, M., 2008. Appraisal of interpretation criteria for the comparative intradermal tuberculin test for diagnosis of tuberculosis in cattle in central Ethiopia. Clin. Vaccine Immunol, $15(8), 1272-1276$.

Ameni, G. and Erkihun, A., 2007. Bovine tuberculosis on small-scale dairy farms in Adama Town, central Ethiopia, and farmer awareness of the disease. Rev. sci. tech. Off. int. Epiz. 26(3), 711-719.

Ameni, G., Aseffa, A., Engers, H., Young, D., Gordon, S., Hewinson, G. and Vordermeier, M., 2007. High Prevalence and Increased Severity of Pathology of Bovine Tuberculosis in Holsteins Compared to Zebu Breeds under Field Cattle Husbandry in Central Ethiopia. Clin Vaccine Immunol., 14(10), 1356-1361. 
Ayele, W. Y., Neill, S. D., Zinsstag, J., Weiss, M. G. and Pavlik, I., 2004. Bovine tuberculosis: an old disease but a new threat to Africa. Int J Tuberc Lung Dis, 8(8), 924-937.

Biet, F., Boschiroli, M. L., Thorel, M. F., Guilloteau, L. A., 2005. Zoonotic aspects of Mycobacterium bovis and Mycobacterium avium-intracellulare complex (MAC). Vet. Rec., 36(3), 411-436.

Cadmus, S. I. B., Agada, C. A., Onoja, I. I. and Salisu. I., 2010. Risk factors associated with bovine tuberculosis in some selected herds in Nigeria. Trop Anim Hlth Prod, 42, 547-549.

Cosivi, O., Grang,e J. M., Daborn, C. J., Raviglione, M. C., Fujikura, T., Cousins, D. et al., 1998. Zoonotic tuberculosis due to Mycobacterium bovis in developing countries. Emerg. Infect. Dis, 4(1), 59-70.

CSA, 2007. Population and Housing Census: Population Size by Age and Sex. CSA Summary and Statistical Report of the 2007. Central Statistics Agency (CSA), Addis Ababa, Ethiopia.

CSA, 2013. Report on livestock and livestock characteristics (private peasant holdings). CSA Agricultural Sample Survey 2012/13. Central Statistical Agency (CSA), Addis Ababa, Ethiopia. pp. 9-13.

De Lisle, G. W., Bengis, R. G., Schmitt, S. M. and O’Brien, D. J., 2002. Tuberculosis in free-ranging wildlife: detection, diagnosis and management. Rev. Sci. Tech, 21(2), $317-334$.

Elias, K., Hussein, D., Asseged, B., Wondwossen, T. and Gebeyehu, M., 2008. Status of bovine tuberculosis in Addis Ababa dairy farms. Rev. sci. tech. Off. int. Epiz, 27 (3), 915-923.

Firdessa, R., Tschopp, R., Wubete, A., Sombo, M., Hailu, E., Erenso, G., et al., 2012. High Prevalence of Bovine Tuberculosis in Dairy Cattle in Central Ethiopia: Implications for the Dairy Industry and Public Health. PLoS One, 7(12), e52851.

Griffin, J., Hahesy, T., Lynch, K., Salman, M., McCarthy, J. and Hurley, T., 1993. The association of cattle husbandry characteristics, environmental factors and farmer characteristics with the occurrence of chronic bovine tuberculosis in dairy herds in the Republic of Ireland. Prev. Vet. Med, 17, 145-160.

Gumi, B., Schelling, E., Firdessa, R., Aseffa, A., Tschopp, R., Yamuah, L. et al., 2011. Prevalence of bovine tuberculosis in pastoral cattle herds in the Oromia region, southern Ethiopia. Trop Anim Hlth Prod, 43(6), 1081-1087.

Gumi, B., Schelling, E., Firdessa, R., Erenso, G., Biffa, D., Aseffa, A. et al., 2012. Low prevalence of bovine tuberculosis in Somali pastoral livestock, southeast Ethiopia. Trop Anim Health Prod, 44(7), 1445-1450. 
Ibrahim, S., Cadmus, S. I. B., Umoh, J. U., Ajogi, I., Farouk, U. M. Abubakar, U. B. et al.,2012. Tuberculosis in Humans and Cattle in Jigawa State, Nigeria: Risk Factors Analysis. Vet. Med. Int., Volume. 2012, Article ID 865924.

Mamo, G., Abebe, F., Worku, Y., Hussein, N., Legesse, M., Tilahun, G., et al., 2013. Bovine tuberculosis and its associated risk factors in pastoral and agro-pastoral cattle herds of Afar Region, Northeast Ethiopia. J. Vet. Med. Anim. Health, 5(6), 171-179.

Mondal, M. A. H., Parvin, M. S., Sarker, S. C., Rahman, A. K. M. A. and Islam, M. T., 2014. Prevalence and risk factors of bovine tuberculosis in cattle in Mymensingh sadar. Bangl. J. Vet. Med, 12(2), 179-183.

Nicholson, M. J. and Butterworth, M. H., 1986. A guide to condition scoring of Zebu cattle. International Livestock Center for Africa (ILCA), Addis Ababa, Ethiopia, pp. 1-29.

OIE, 2008. Bovine tuberculosis. OIE manual of diagnostic tests and vaccines for terrestrial animals (mammals, birds and bees). Office International des Epizootics (OIE), Paris, France. pp. 683-617.

O'Reilly, L. M. and Daborn, C. J., 1995. The epidemiology of Mycobacterium bovis infections in animals and man: a review. Tubercle Lung Dis., 76, 1-46.

Pandey, G. S., Hang'ombe,B. M., Mushabati, F. and Kataba, A., 2013. Prevalence of tuberculosis among southern Zambian cattle and isolation of Mycobacterium bovis in raw milk obtained from tuberculin positive cows. Vet World, 6, 986-991.

Proaño-Perez, F., Benitez-Ortiz, W., Celi-Erazo, M., Ron-Garrido, L., BenitezCapistros, R., Portaels, F., et al., 2009. Comparative Intradermal Tuberculin Test in Dairy Cattle in the North of Ecuador and Risk Factors Associated with Bovine Tuberculosis. Am. J. Trop. Med. Hyg, 81(6), 1103-1109.

Renwick, A. R., White, P. C. L. and Bengis, R. G., 2007. Bovine tuberculosis in southern African wildlife: a multi-species host-pathogen system. A review. Epidemiol Infect, 135, 529-540.

Romha, G., Gebre egziabher, G. and Ameni, G., 2014. Assessment of bovine tuberculosis and its risk factors in cattle and humans, at and around Dilla town, southern Ethiopia. Anim. Vet. Sci., 2(4), 94-100.

Tamiru, F., Hailemariam, M. and Terfa, W., 2013. Preliminary study on prevalence of bovine tuberculosis in cattle owned by tuberculosis positive and negative farmers and assessment of zoonotic awareness in Ambo and Toke Kutaye districts, Ethiopia. J. Vet. Med. Anim. Health, 5(10), 288-295. 
Thakur, A., Sharma, M., Katoch, V. C., Dhar, P. and Katoch, R. C., 2010. A study on the prevalence of Bovine Tuberculosis in farmed dairy cattle in Himachal Pradesh. Vet World, 3(9), 409-414.

Thrusfield, M., 1995. Veterinary epidemiology, 2nd ed. Balckwell Publishing Company, Oxford. pp.182-187.

Tigre, W., Alemayehu, G., Abatu, T. and Deressa, B., 2011. Preliminary study on public health implication of bovine tuberculosis in Jimma town, South West Ethiopia. Global Vet, 6 (4), 369-373.

Torrell, R., 1998. Methods of determining age in cattle. Cattle Producer's Library: CL712. University of Nevada, Reno, NV.

Tschopp, R., Schelling, E., Hattendorf, J., Aseffa, A. and Zinsstag, J., 2009. Risk factors of bovine tuberculosis in cattle in rural livestock production systems of Ethiopia. Prev Vet Med, 89(3-4), 205-211.

Tschopp, R., Bobosha, K., Aseffa, A., Schelling, E., Habtamu, M., Iwnetu, R., et al., 2011. Bovine tuberculosis at a cattle-small ruminant-human interface in Meskan, Gurage region, Central Ethiopia. BMC Infect Dis, 11, 318.

Wilkins, M. J., Meyerson, J., Bartlett, P. C., Spieldenner, S. L., Berry, D. E., Mosher, L. B. et al., 2008. Human Mycobacterium bovis Infection and Bovine Tuberculosis Outbreak, Michigan, 1994-2007. Emerg. Infect. Dis., 14, 657-660.

Zeru1, F., Romha, G., Berhe, G., Gezahegne Mamo, G., Sisay, T., and Ameni, G., 2014. Prevalence of bovine tuberculosis and ssessment of Cattle owners' awareness on its public health implication in and around Mekelle, Northern Ethiopia. J. Vet. Med. Anim. Health, 6 (6), 159-167.

Zinsstag, J., Schelling, E., Roth, F. and Kazwala, R., 2006. Economics of bovine tuberculosis. In:, Thoen, C. O., Steele, J. H. and Gilsdorf, M. J. (Ed.), Mycobacterioum bovis Infection in Animals and Humans Ames, IA: Blackwell Scientific, pp 68-83. 